This is the author final version of the article accepted for publication. The published article can be found here:

https://doi.org/10.1080/19415257.2019.1689525

\title{
What matters in learning communities for inclusive education: A cross-case analysis
}

\author{
Elizabeth Walton $^{\mathrm{ab}}$, Suzanne Carrington ${ }^{\mathrm{c} *}$, Beth Saggers $^{\mathrm{c}}$, Chris Edwards $^{\mathrm{c}}$ \\ and Wacango Kimani ${ }^{\mathrm{b}}$
}

${ }^{a}$ School of Education, University of Nottingham, Nottingham, UK; ${ }^{b}$ School of

Education, University of the Witwatersrand, Johannesburg, South Africa; ${ }^{c}$ Faculty of

Education, Queensland University of Technology, Brisbane, Australia

*Corresponding author: Professor Suzanne Carrington, Faculty of Education, Queensland University of Technology, Victoria Park Road, Kelvin Grove QLD 4059 Australia. Email: sx.carrington@qut.edu.au

Author biographies:

Elizabeth Walton is an Associate professor in special and inclusive education in the School of Education at the University of Nottingham. She teaches on the face-to-face and online MA courses in Special and Inclusive Education as well as supervising postgraduate research in aspects of inclusive education. She is a member of the forum of the UNESCO Chair for Teacher Education for Diversity and Development and is also a visiting Associate Professor at the Wits School of Education in Johannesburg South Africa. Her research interests include teacher education for inclusive teaching, the knowledge of inclusive education, exposing exclusion and enabling inclusion in education.

Suzanne Carrington is a Professor and Associate Dean (Research) in the Faculty of Education, Queensland University of Technology (QUT), Australia. Suzanne's areas of expertise are in inclusive education, disability, and teacher preparation for inclusive schools. She has engaged in research to inform policy and practice in Australian and international education contexts, more recently extending this research to the South Pacific and Asia. She has broad knowledge of education research, and her publication list provides evidence of extensive collaboration with education, health, and medical research. 
Beth Saggers is an Associate Professor in the School of Early Childhood and Inclusive Education at Queensland University of Technology (QUT). She currently lectures in Autism Spectrum Disorders (ASD), catering for diversity, inclusive practices, and behaviour support. She has almost 30 years of experience working with students on the autism spectrum across a range of age groups and educational settings. She is an active research participant in the national Autism Cooperative Research Centre (Autism CRC). Her research interests include developing supportive learning environments for students with autism, the perspectives of key stakeholders, and supporting challenging and complex student needs.

Chris Edwards is a full-time PhD student in the School of Early Childhood and Inclusive Education at Queensland University of Technology (QUT). His doctoral research explores an innovative approach to service delivery, utilising tele-consultation to support educators of young students on the autism spectrum in rural and remote regions. He has a background in behavioural science (psychology) and prior experience supporting a diverse range of learning needs in children to adults.

Wacango Kimani is a full-time PhD student in the School of Education at the University of the Witwatersrand. Her doctoral research on professional learning for inclusive pedagogy focuses on teacher professional identity and agency in professional learning communities. She previously conducted voice research with young schooling mothers. She holds post-graduate qualifications in inclusive education and information science. 


\section{What matters in learning communities for inclusive education: A cross-case analysis}

Implementing inclusive education requires on-going commitment to teachers' professional learning. One way of implementing professional learning is to develop learning communities based on Lave and Wenger's ideas of situated learning and learning as social practice. Learning communities, drawing on models of Professional Learning Communities and communities of practice, were designed to build capacity for inclusive teaching in two rural schools in Australia and a peri-urban school in South Africa. This paper reports on a multi-case study that involves a cross-case analysis of these three learning communities. We demonstrate that across the three cases, responsiveness to contextual exigencies matters, expertise matters and supportive networks matter. These findings are further illuminated by complexity theory which draws attention to learning communities operating at the confluence of a number of interacting systems, as well as the possibility of change where teacher learning occurs through the recontextualisation of knowledge and learning across boundaries. Our findings support situated learning that values collaboration to develop social and inclusive cultures and practice in schools. The findings also have the potential to inform planning for professional learning for inclusive education.

Keywords: inclusive education; communities of practice; professional learning communities; professional learning; complexity theory

\section{Introduction}

Inclusive education is a global agenda designed to address exclusion from and within education systems. It is underpinned by human rights, equity and social justice and is often, though not exclusively, concerned with the educational inclusion of people with disabilities. The implementation of inclusive education is hampered by several factors, one of which is inadequate teacher education (Sharma et al. 2008). To address this, countries have implemented various professional development activities designed to enhance teachers' capacity for inclusive teaching, which we take to mean pedagogical 
responsiveness to the needs of diverse learners. The most promising of these activities are learning communities based on Lave and Wenger's (1991) ideas of situated learning and learning as social practice. We suggest that learning communities connect teachers, build on expertise available in the school community and build a common language of practice. Research has described the workings of these communities within specific contexts, but not much is known about the key components of these learning communities across contexts. This paper focuses on learning communities designed to build capacity for inclusive teaching in two rural schools in Australia and a peri-urban school in South Africa. We answer 'What matters?' across these learning communities. The paper begins with an overview of inclusive education and the varied success of professional development programmes that have supported knowledge, inclusive beliefs and attitudes, and changes in pedagogical approaches. This is followed by a discussion of Lave and Wenger's work that focuses on how learning as social practice has influenced alternative ways of supporting teacher learning. Case studies from Australia and South Africa are used to highlight the complexity of teacher learning. A multi-case study (Stake 2006) involving a cross-case analysis of three learning communities is presented. We are able to show that across the three cases, responsiveness to contextual exigencies matters, expertise matters and supportive networks matter and using Stake's approach (2006), seven assertions are developed from the cross-case analysis. The assertions have the potential to inform planning for professional learning for inclusive education, particularly in schools that serve a diverse range of learners. The findings support situated learning that values collaboration to support social and inclusive cultures and practice in schools. 


\section{Professional learning for inclusive education}

\section{Inclusive education}

Inclusive education has grown as an international movement to not only support learners with disabilities, but to promote equitable access, success and participation in education for all. Inclusive education is endorsed by the widely ratified United Nations (UN) Convention on the Rights of Persons with Disabilities (CRPD) (UN 2006) and also Sustainable Development Goal Four, which is to 'Ensure inclusive and equitable quality education and promote lifelong learning opportunities for all' (UN 2015). Both Australia and South Africa are committed to inclusive education and both are signatories to the CRPD.

Despite its foundation in the discourses of human rights, educational equity and social justice, and the various international and country policies promoting inclusive education, its implementation across and within countries has been uneven. Reasons for this include uncertainty about what is meant by inclusive education (Szumski et al. 2017), inadequate time and resources (Chiner and Cardona 2013), sedimented exclusionary practices (Slee 2011) and inadequate teacher education (UN 2016). These are all important issues that need attention in the quest to resist exclusion, and they are certainly all imbricated. However, for this study, we focus on teacher education, with particular attention to the professional development of practicing teachers and other support personnel in schools.

\section{Teacher education for inclusive education}

Teaching is a professional practice which demands expert knowledge, ethical service and continuous learning (Hargreaves and Fullan 2012). The specific knowledge base required for inclusive teaching has been elaborated elsewhere (see Florian and Rouse 
2009 and UN 2016) and focuses on knowledge of learning, development and student diversity; knowledge of curriculum, pedagogy and assessment; and knowledge of collaborative teaching and learning. The ethical demand of inclusive teaching is to transform social norms to ensure that everyone is included in the learning environment (Florian and Graham 2014). The need for continuous learning becomes ever more important as classrooms change, particularly as they become more diverse.

Teachers worldwide are seen to be un(der)prepared to meet the diverse learning needs of their learners (Forlin 2010, Spratt and Florian 2013). This is supported by research in both Australia and South Africa. Recent research about Australian teachers' preparation and confidence to teach learners on the autism spectrum is an example: The Australian Autism Educational Needs Analysis (ASD-ENA) (Saggers et al. 2018) conducted a nationwide survey $(\mathrm{N}=1468)$ collecting data from educators, specialists, parents and learners on the autism spectrum (age 11-18 years). One of the key barriers identified by the participants was the lack of suitable education and training for the educators to effectively support their learners on the spectrum. Two South African studies (Ntombela 2011 and Engelbrecht et al. 2016) in different regions of the country both confirm that teachers regard a lack of training as a significant factor that impedes inclusive practice.

Various initiatives have been undertaken to address this, with training provided by universities, education departments, non-government organisations and education consultants. Often, though, these once-off activities do not result in the shifts needed for sustained inclusive practice. In South Africa, for example, teachers have given positive responses after attending in-service learning programmes, stating that they find the learning programmes beneficial and that they are in favour of the principles of inclusive education. However, months later they report that they lack the competence to 
incorporate inclusive practices in their teaching (Walton et al. 2014). From this and other studies it would seem that workshops and short courses have made minimal difference to teachers' perceptions towards inclusion in this country (Lessing and De Witt 2007). Similarly, in Australia, when asked about their preferences for professional learning as part of the ASD-ENA, teachers highlighted in their top five preferences: 1. face-to-face professional development from a professional organisation; 2. observation of others' practice (real life); 3. face-to-face seminars; 4. professional support methods (e.g., coaching); and 5. observation of others' practice (online) (Saggers et al. 2018).

The inadequacy of the short course or workshop is noted in the wider literature on teacher professional learning. Short courses or workshops are criticised for being fragmented (Borko 2004) and not necessarily tailored to teachers' needs (Robinson and Carrington 2002). Teachers resent being lectured by outside experts who do not have a long-term relationship with them or the school (Russo 2005). There is often a lack of follow-up support (Robinson and Carrington 2002). Despite this evidence, traditional teacher training and support methods, such as didactic instruction and in-service workshops, continue to be a primary source of professional development and support for classroom teachers (Gilchrist 2018) even though they have been shown to be inadequate methods of support on their own (Walton et al. 2014).

In contrast, it is often recommended that professional learning and support for classroom teachers should take place in the natural environment, such as the school (King-Sears et al. 2000), because the specific context needs to be carefully considered (Vangrieken et al. 2017). Professional learning conducted in this manner consists of feasible, embedded strategies which include teacher collaboration and problem solving as well as adequate social and administrative support to ensure sustainability and support for teacher efficacy (Pirtle and Tobia 2014). 


\section{Professional learning in collaborative communities}

Collaborative learning has the potential to provide an environment in which communities create professional knowledge through interaction in a way that challenges previous assumptions and creates new meanings (Timperley 2011). Creating time and opportunity for staff to learn and work with each other supports shared conversations, reflection on practice, consideration of assumptions and knowledge and planning to address challenges in context (Messiou et al. 2016). Lave and Wenger (1991) and Wenger (1998) challenge the separation of learning from other social activities, and argue that learning happens everywhere and is a social process of participation. Learning, according to Lave (1991, p. 65), is becoming a member of a 'sustained community of practice'; of people who engaged in a 'shared domain of human endeavor' (Farnsworth et al. 2016, p. 140). Communities of practice is an overarching concept that explains both formally and informally constituted communities which are 'groups of people who share a concern, a set of problems, or a passion about a topic, and who deepen their knowledge and expertise in this area by interacting on an ongoing basis' (Wenger et al. 2002, p. 4). While communities of practice are not unique to supporting teachers, their application has been widely studied as a method of extending and strengthening knowledge and expertise around an issue through ongoing interaction and collaboration (Wenger et al. 2002, p. 4). Wenger and colleagues (2002) proposed that there were three structural elements (domain, community and practice) of a community of practice, and that they created an ideal knowledge structure when functioning well together. The domain of knowledge described the common interest or overarching goal that gave meaning and inspired the actions of members. The community refers to the members that interact regularly and collaboratively in social domains to support their shared interest. Finally, the practices describe the techniques 
and strategies that members develop, share and maintain to further support this domain.

A variety of learning communities have emerged based on Lave and Wenger's work, all of which aim to support teacher professional development that is sustained over a long period of time (Wenger et al. 2002) and to reconstruct teaching practices and beliefs through active learning (Mak and Pun 2015). Various instantiations of learning communities have slightly different emphases. Vangrieken et al. (2017) find that government initiated teacher communities focus on implementing education standards while those initiated by a school principal or teachers focus on sharing ideas, exchanging teaching strategies and planning lessons for a subject matter. Professional Learning Communities (PLCs) are sometimes distinguished from communities of practice as being specific to the educational context (Vangrieken et al. 2017) and having the specific focus on learning for the improvement of practice for the benefits of learners. In other words, 'professional' is a distinguishing characteristic, demanding that these learning communities have a knowledge focus (Brodie and Borko 2016).

Professional learning in communities has been well researched in many teaching domains. Studies attest to its positive outcomes in early childhood education (Christ and Wang 2013), secondary mathematics education (Brodie 2016) and for low and underachieving middle years learners (Berry et al. 2005). Less is known, however, about the impact that this type of learning can have upon supporting educators to better support children with diverse learning needs in inclusive classrooms (Botha and Kourkoutas 2016). In their study across 25 English schools, Ainscow et al. (2006) saw value in framing collaborative learning for the development of inclusive practices as communities of practice, although they do stress that strengthening communities of practice does not constitute a 'simple route' (p. 132) to developing these practices. A study conducted in Australia by the Victorian Government Department of Education 
and Training (2015) showed promising results for the support of learners on the autism spectrum with reports of higher levels of teacher capabilities and increased level of school confidence. A small-scale South African study showed the value of 'social collaborative learning' (Swart and Oswald 2008, p. 104) as teachers formed groups to support their learning for inclusive education. While these examples all show promise, their findings are contextually constrained. We wanted to know what elements of learning in communities for inclusive teaching transcend context, and thus offer a way forward for those designing and engaging in this work.

\section{Research design and methodology}

A complexity theory framework is used to consider what matters in three learning communities for inclusive teaching in Australia and South Africa. Complexity theory draws on complexity science and Davis and Sumara (2005, p. 315) suggest that this 'might actually be useful to educators and educational researchers in their ongoing efforts to understand how one might make effective and deliberate interventions in systems that do not always respond in predictable ways'. This theory informs our understanding that teacher professional learning needs to be contextually situated (Anderson et al. 2000). We consider teacher learning not as an event, but as a complex process incorporating the individual teacher, the learning activity, and the wider institutional and social context (Opfer and Pedder 2011). Through complexity theory, we are able to pursue 'a more dynamic understanding of teacher professional learning in an attempt to conceptualize this complex process' (p. 377).

This is a multi-case study (Stake 2006) involving a cross-case analysis of three learning communities. This choice of research design is appropriate because we wanted to closely examine three cases that were linked together. While the country contexts 
might be quite different, each site had a type of learning community with a focus on developing capacity for inclusive teaching to support learners with diverse learning needs. The three cases 'have their own stories to tell' (Stake 2006, p. vi) but in this paper, the focus is on 'the phenomenon exhibited in those cases' (p. vi). Stake calls the phenomenon a 'quintain' which is what we seek to understand through a multi-case study. In our research the quintain is teacher learning in a learning community. We consider what matters in these three learning communities that supports and promotes learning for inclusive teaching.

\section{Settings}

Case study 1 (South Africa): City Primary

City Primary is a peri-urban, government primary school in South Africa. It serves over 1700 learners from low socio-economic backgrounds, and as a 'full-service school', includes learners with disabilities. The school is under-resourced with high learner to teacher ratios and space constraints.

\section{Case study 2 (Australia): Charlie School}

Charlie School is a co-educational government school situated in outer regional Central Queensland Australia. This very small rural school with a teaching principal caters for a small community of learners of compulsory school age from their Preparatory year (5 years of age) through to Year 6 (11 years of age) and welcomes learners with disabilities. One class caters for the early years (Prep, Years 1, 2 and 3) while the other classroom caters for Years 4, 5, 6 and 7. 
Case study 3 (Australia): Echo School

Echo School is a co-educational government school situated in a small rural farming town (population of 574) in outer regional Central Queensland Australia. The small rural school caters for learners of compulsory school age from their Preparatory year (5 years of age) through to Year 12 (17 years of age) and welcomes learners who have disabilities. Some high school subjects are offered through the School of Distance Education when staffing constraints prevent them from having suitably trained staff in all specific subject areas. Staff turnover is moderate.

\section{Professional Learning Communities (PLCs) - Case study 1}

PLCs were established in City Primary school as a university-community engagement project. This was a new initiative designed to support teacher learning for inclusive teaching in a 'full-service school' (Walton 2016). The PLCs comprised groups of six to eight teachers of the same grade. As directed by the school principal, all teachers in the school participated in the PLC groups, which met four times a year. The meetings took place on the same day, with groups clustered around tables in the large staff room. The university team, comprising teacher-educator lecturers and post-graduate students, developed material and guidelines for the PLC meetings. The meetings themselves were facilitated by teachers, usually grade leaders, who were selected by the principal. The facilitators met with the university team in advance of the PLC meetings to familiarise themselves with the topic and material (Matanhire 2017). At least two members of the university team were present during the PLC meetings, circulating among the groups to answer questions and clarify concepts. The research component of the project investigates the development and entrenchment of sustainable and effective PLCs for inclusive teaching in full-service schools. 


\section{Participants}

Participants in this case study are the teachers and facilitators of the PLCs. Over the three years of data collection, 40 teachers took part in one or more PLC meetings, and all gave written consent for their conversations in the meetings to be recorded. A further 11 teachers were interviewed about their experience of the PLCs and their perceptions of their learning. Concerns of participants for the protection of their anonymity has meant that we were not able to gather biographical details and we have committed not to reveal information that could identify the school. We are able to note that the participants were predominantly black South African women, with a range of ages and experience. We understand that many are regarded as underqualified, not having the full four year certification currently required. This is in keeping with the overall profile of South African teachers (Hofmeyer and Draper 2015).

\section{TeleConsultation approach - Case studies 2 and 3}

The focus in case studies 2 and 3 was to explore how a TeleConsultation Classroom (TCC) approach could support a community of learning for educators who were supporting learners on the autism spectrum in inclusive settings. TCC approaches use electronic communications and technology to provide support when distance separates the participants (Darkins and Cary 2000). The use of TCC to overcome professional isolation and implement support and services to rural regions is a growing area of research. Although application of TCC is becoming increasingly prominent to provide health and specialised services to rural areas, there is limited application in educational contexts. The TCC approach used a range of electronic communication options (e.g., phone, email and video conferencing) dependent on the needs of the educators to implement a consultative approach between educators and parents in rural, remote, 
Indigenous and isolated communities and specialist support staff in metropolitan areas. The aim was to consider the existing elements of a community of practice evident in the two contexts that were in rural areas of Queensland, Australia and to consider how the TCC approach influenced the development or strengthening of a community of practice in the two contexts and improved the skills, knowledge and problem solving of the school communities to better meet student and family needs.

\section{Participants}

Participants for case studies 2 and 3 were the educators at Charlie School and Echo School who worked alongside the specialist team from the Autism Specific Service Provider (ASSP team) to better support their young student on the spectrum. The autism specific specialist team included an occupational therapist, speech therapist and educational consultant all with autism specific knowledge. While the focus of the study was on the educators within the schools, the ASSP team offered a unique and knowledgeable perspective. The educators in the study were selected given their involvement in the community of learning/practice that focused on supporting students on the autism spectrum.

\section{Data collection}

\section{Case study 1}

The primary data source is the transcribed conversations that teachers had in their PLCs from 2014-2016. A total of 11 meetings were recorded and transcribed. This was supplemented by semi-structured individual interviews conducted with 11 teachers to validate and augment the information that was obtained from the PLC audio recordings and to clarify queries that had surfaced in the preliminary data analysis (McMillan and 
Schumacher 2010).

\section{Case studies 2 and 3}

Data were collected through two phases during 2017/2018 and aligned with a preintervention and post-intervention stage. The intervention was the implementation of TCC to support a community of learning. Data were collected using the methods of semi-structured interviews in 2017 and 2018 and note taking during the interviews and observations.

\section{Data analysis}

Each individual case discussed in this paper has been analysed in detail and the results have, and continue to be, reported elsewhere. When analysing data from across the three case studies, we were interested to consider the complex systems and subsystems that influenced teacher learning such as 'local knowledge, problems, routines, and aspirations' (Opfer and Pedder 2011, p. 379).

Complexity theory influenced analysis of data from the three cases with the intention of studying the issues that 'cut across cases' and understand how they '[contribute] to the quintain' (Stake 2006, p. vi). As a group of researchers working across international contexts, we were seeking to understand how teacher professional learning was contextually situated and how the learning supported and promoted change in practice for inclusive teaching. The research team used the evidence from the case studies to understand and highlight similarities or disparities across the cases that characterise the quintain.

The data from each case was cross-analysed to understand the commonality and the differences across the contexts. The findings from each case contribute to the complex meaning of the quintain (Stake 2006). The researchers worked on a collective 
interpretation across the cases and data were organised under three themes: context matters; expertise matters; and supporting networks matter. These themes organise the data so that we can report on the quintain and preserve the main question for the overall study: What matters in these learning communities? Findings from the cross-case analysis are called 'assertions' (Stake 2006, p. 41). The listed assertions correspond to each theme and are made about the quintain.

\section{Findings}

The cross-case analysis resulted in three themes reporting on the quintain of teacher learning in learning communities. Within each theme a number of assertions were developed.

\section{Theme 1: Context matters}

The importance of context is emphasised in the literature on inclusive education (Kozleski et al. 2011). When it comes to teacher learning in communities for inclusive education, the importance of context is magnified. Across the three cases, it is clear that contextual specificities impact both inclusive teaching practices and the functioning of the learning community, and these in turn impact each other. We make the following assertions in this regard:

\section{Assertion 1.1: Contextual demands directly impact the functioning of the group}

Across the three schools, the workplace demands on the teachers have a negative impact on their engagement in learning communities. In City Primary (South Africa), teachers are recorded as coming to the PLC meetings at the end of the day being 'so tired' and then being anxious to leave as soon as possible to return to their classrooms because they 'have a lot of work in class'. Both Australian schools have very small numbers of 
staff. This means that staff have to 'fulfil a number of different roles across the day', there is an unavailability of relief teachers in the case of illness and, as a teacher aide at Charlie School says, 'When you have very challenging situations or challenging students that require a one on one ... Like we don't take morning tea and lunch breaks, we're sort of on the ground'. This pressure on time and the 'multi-tasking of doing all that and being super organised' leaves little time and capacity for engaging with the learning community. These findings echo King's (2019, p. 169) comment that educators 'struggle to find the time and space' for the conversations needed to develop collaborative professional learning in the quest for inclusion in schools.

\section{Assertion 1.2: Contextual factors constrain inclusive teaching and hence the} functioning of the learning community

Inclusive teaching in each of the schools is constrained by factors outside teachers' control. A lack of material resources is mentioned as a challenge in both City Primary (South Africa) and Echo School (Australia). Particular school conditions also impact teachers' ability to be inclusive. In City Primary, teachers note that they have high learner teacher ratios with no teaching assistants. Charlie School (Australia) has multiage classrooms where the teaching principal has to teach every grade from 'prep to year six', including 'special needs children'. The principal of Echo School explains that bringing about change towards more inclusive practice is difficult in a small rural town where people 'don't like change ... because it doesn't pose any discomfort for them'. Contextual challenges are commonly reported by those attempting to implement inclusive education (Australian Research Alliance for Children and Youth 2013, Engelbrecht et al. 2016), but we assert that these challenges further impact the functioning of learning communities. In City Primary, for example, a conversation in the PLC about an inclusive teaching strategy is shut down through reference to 
contextual challenges:

T(Teacher)1: It doesn't work. Even with the Grade 2s it doesn't work I'm telling you.

T2: Ay, it doesn't work.

T3: How can it work with 40 something?

T1: We need assistant teachers.

The learning communities are intended to help teachers work within the challenging contexts, but at times the difficulties that teachers experience seem insurmountable and effectively truncate conversations in the learning communities. This is not always the case, as the third assertion demonstrates.

Assertion 1.3: Context-specific challenges of inclusive teaching can be addressed in the learning community

Through discussion in learning communities, teachers are able to contextualise their learning and consider how inclusive teaching strategies can be adapted to meet context specific challenges. One PLC meeting in City Primary (South Africa) watched a video about a co-operative learning strategy which couldn't be directly translated into their context due to space constraints. The teachers discussed ways in which they could adapt the strategy for implementation in their context:

T1: The practicality of it now in our classes since we are forty something ...

T2: Since ...

Facilitator: No, no we can't use the mat. I'm thinking ...

T2: Yes

Facilitator: (Demonstrating) ... say it's a desk, it's a desk and it's another desk

T3: $\mathrm{Mmm}$

Facilitator: We are two, two

T2: Three, two, two

Facilitator: So like this, these two, you pair them, they work together

T4: Ja [Yes] 
T5: So it means we have to change the arrangement.

In this extract, with the guidance of the group facilitator, the learning community devises a way to circumvent the lack of space to do a mat activity and works out how to configure desks to make the co-operative learning technique possible.

The findings within the Australian case studies further support this assertion. A notable example was evident within a pre-intervention discussion between staff at Charlie School and the ASSP team. The school staff described how the autistic student was struggling with an overload of visual stimuli in the classroom, but that these visuals supported the other learners. The staff observed sessions at a different autism specific early intervention provider to see how they effectively found this balance. The learning community discussed how what they observed would not suit Charlie School and had to be adapted to their specific context. This was done by taking the student to a separate room without the visual stimuli on the walls in order to reduce anxiety.

Teacher Aide: We went and observed at [other provider], and were, 'so that's how it works'. But it's not going to work like that at Charlie School with one staff member is it? So, he [student] wasn't coping very well at all. So, we spent a lot of time down here in the bird building, here by himself. We had everything off the walls and had a great inclusion coach last year that said, 'look he needs to be in a room by himself for a few hours a day'.

ASSP Professional Learning Facilitator: We call it pre-teaching. You know, preteaching those skills in order to be in the classroom with other children. We need to give him the skills in a safe area outside of that class.

These extracts demonstrate the potential of dialogue within learning communities to recontextualise knowledge for inclusive teaching. The learning community offers a generative space in which teachers can mediate knowledge that comes from outside the context, and finds ways to make it contextually relevant and applicable. 


\section{Theme 2: Expertise matters}

Knowledge development and exchange is important to ensure that the communities are in fact learning communities. This theme draws attention to the importance of expertise as a source of knowledge for professional learning in communities. Here we make two assertions:

\section{Assertion 2.1: Local knowledge is valued expertise}

The knowledge of members of the learning community is a valuable resource. Expert knowledge is not necessarily knowledge external to the school. The teachers in one PLC in City Primary (South Africa) explain that 'we are sharing information [which] is a form of training, okay, where we are, not someone who is sitting and telling you - we all know something and we all can share'. In Charlie School (Australia), the speech therapist in the community of practice affirms the value of the teachers' knowledge of children saying,

\footnotetext{
... through discussion we found that staff had already had really fabulous ideas and because they knew the child so well. They knew the sorts of things that would work for him so a lot of the time we would just you know, agree and reinforcing things that had already been thought of by the staff working with him.
}

Local expertise might be experience with teaching strategies, knowledge of pupils and their background, and familiarity with local policies and processes. The value of local knowledge in the development of inclusive practice is documented in the literature (see Walton 2018, Carrington et al. 2019). Learning communities provide the space where this knowledge can be recognised and developed to build contextually responsive instantiations of inclusive education. 
There is a danger that without external expert knowledge, learning communities would encounter 'horizons of observation' (Little 2003 cited Vescio et al. 2008, p. 89). These horizons are the limits of the environment as a learning context, teacher positionality and preconceived ideas. Without external knowledge, learning communities can be a mechanism for recycling existing patterns of thinking and reinforcing the status quo. In the case study schools, external expert knowledge of how to be pedagogically responsive to diverse learners is valued by the learning communities in two domains. The first is with reference to 'special needs' or disability and teaching strategies that promote learning success for all. Teachers in City Primary (South Africa) request 'development' on working with learners who experience learning difficulties that goes beyond their mutual sharing of ideas in the PLC. In this regard, one teacher asks a member of the university team who was circulating among the groups,

Are you also going to help us with some of the ways that we can use to help these learners in the class, because most of the time it's like us, us, us talking and you are not giving us any development?

A teacher in Charlie School (Australia) expresses how helpful it is to have a 'partnership with those people that are experts'. She explains that,

Being able to access people from ASSP who are the experts or hold a lot of that professional specific knowledge in relation to autism will be really really useful for the staff. Because I think that's where we struggle, accessing that information but also in a timely manner as well.

The value of expertise in this domain is reiterated by Florian and Rouse (2009, p. 600) who note that 'Inclusive practice will reflect actions that are collaborative, drawing on the expertise of specialists without relinquishing responsibility for teaching all learners'. 
The expert knowledge that learning communities value goes beyond information about special needs or disability. Teachers in City Primary recognise that they use some of the teaching strategies presented to them by the university team, but appreciate that 'it's here and systematically compiled, it's easy for every teacher to implement it to the benefit of the child'. In this regard, teachers value the work done by the university team in codifying principles of practice and thereby systematising their learning.

The second domain is that of community knowledge. Echo School draws on the external expertise of elders in the local community to ensure culturally appropriate language and practice. A teacher explains,

We actually invite people from the community and the elders from the community in to just to discuss different ways of teaching and learning and especially with the Indigenous language ... there are certain things that we have to ask permission for, and we also like to get information as to whether we are pronouncing words right or other words where teaching the correct, are we doing by their culture properly.

These findings align with previous Australian research that supports the significance of collaborating with members of the Aboriginal community. It is through consultation with Aboriginal elders and leaders that an education programme can have an increased chance of success through better understanding of Aboriginal pedagogy and cultural values (Duley et al. 2017).

External expertise is thus recognised by participants as crucial for their learning in communities and for their inclusive practice. It provides learning communities with specific knowledge about teaching children with particular support needs, it systematises pedagogical knowledge to make it accessible and it addresses recognised gaps in cultural knowledge. 


\section{Theme 3: Supportive networks matter}

This theme emphasises the community aspect of learning communities and we make two assertions here:

\section{Assertion 3.1: Collaborative learning and mutual support are valued}

Learning in a community breaks down isolation and builds professional practice through mutual support and collaboration. Teachers in City Primary (South Africa) are explicit that they value the interaction PLCs offer in contrast to traditional workshopstyle professional development activities. One says,

\footnotetext{
With PLC we get to interact ... you be part of the topics or whatever is being taught that day. With the workshops, they tell you; whether you do it or you don't, they don't even follow up. But here you get to implement it in the class. It's practical, it's not like something that you get told and then you forget.
}

The PLC creates the opportunity for teachers in City Primary to share challenges and to offer collegial support. A teacher reveals in an interview that, 'We share ... our challenges in the classroom and ... [we] are also able to help each other on the solutions that we can come up with to help each other in the classroom'. As a result of their learning in the PLC, teachers in City Primary report teaching in more inclusive ways. One teacher explains in an interview that,

Now I don't only focus on the ones with higher understanding or ability - I find pleasure as well in helping the ones who are struggling, that I don't leave them out ... Before I was just focusing on the ones that I knew they're going to understand.

Collaborative learning and mutual support in a learning community builds teacher confidence and contributes to better outcomes for learners. A teacher aide in Charlie School explains this as, 
I think just working together ... you feel more comfortable with your choices when you can bounce off other people, communicate with other people, feel that you're supported by so many other people. The kids, the students get such a sense of security from knowing, from seeing that whole community involved in their education. I think they probably benefit the most, but the staff - it's so much easier each day to do the best that you can do knowing that there's so many other people out there to support you with. If you have a bad day or if you need help with a situation you can't resolve yourself.

In Echo School too, the learning community provides support in difficult circumstances and builds capacity for improved practices. An ASSP team member comments on a teacher who,

... knew that we were there in a supportive capacity and not a judgemental capacity and I think she was very welcoming of that fact and the idea that she might be able to improve her practices and that maybe we would be able to reduce her load a little bit.

This assertion is highly congruent with what is already known about the value of collaboration and support in teacher learning communities. These data specifically emphasise how learning in community leads to teachers feeling supported to be able to meet a range of learning needs. This assertion thus has particular salience for the development of inclusive practice in schools.

\section{Assertion 3.2: Ongoing and regular communication is important}

Learning communities might be more or less structured in terms of time and frequency of meeting. But the sustained implementation of inclusive teaching requires ongoing communication among community members. Formal PLC meetings in City Primary (South Africa) took place at least once per school term, and the learning was supported through ongoing discussions among teachers outside the meeting. One reported that 
'After PLC ... We usually do discuss it [the PLC topic], as grade 1 [teachers]. We talk to each other with the topics or what we teach'. Reciprocal relationships among learning community members is emphasised in Charlie School where an ASSP team member says,

I think the really important part with any relationships between schools and professionals is it needs to be a two way relationship and that, it needs to have that back and forth between professionals and the schools for it to work. It needs to be a partnership.

Regular communication is necessary for the sedimenting of inclusive practices. The principal of Echo School explains:

So, having a framework or having a person or a team that are checking in on a regular basis and there's an expectation that a certain amount of status quo is being maintained then it's more likely that you know, those things might become more embedded.

The speech therapist working as part of the team to support case studies 2 and 3 sees the teleconferencing as a means to sustain relationships as well as providing realtime support:

Now that we've sort of seen each other in real life, that's a really good starting point to be able to now use the tele-conferencing to um, maintain that relationship when we can't be there in person. And I think yeah, I can see the tele-conference going to be um, a good way of kind of reinforcing things that we'll be speaking about because it will be real time. You know, potential to ask questions in real time and clarify things that perhaps in writing wouldn't be so clear.

All three case study schools found mechanisms to sustain the communication and relationships that constituted the learning community. This was through regular and 
scheduled learning community meetings (in person or TCC) and revisiting learning in other conversations.

\section{Discussion}

Isolating what matters in learning communities for inclusive teaching does not mean that we regard the phenomenon (quintain) as an accretion of the identified factors. Instead, we find these factors operating across all three cases in ways best understood through complexity theory.

Context matters in ways beyond establishing the 'relevance' of teacher learning activities. The learning communities we investigated operate at the confluence of a number of interacting systems, each of which is a complex context in itself (CochranSmith et al. 2014, Trombly 2014), and each of which exerts different influences on the learning community. These systems include the international and national imperatives for the implementation of inclusive education; the wider community context in which the school operates; the particular school's configuration; the 'external' stakeholders in each learning community; and, of course, the individuals who participate in the community. Context is thus highly complex and developing inclusive teaching practices in different contexts requires inclusive approaches to professional learning that recognises this. Including the views of people in the school community is an inclusive approach to professional learning. Linear, or input-output approaches to professional learning may be less able to navigate the complexity of context, whereas collaborative, supportive and respectful learning communities, drawing on expert knowledge about inclusive teaching, may be better positioned to do so.

The potential for change in response to contextual exigencies is more likely with knowledge recognised and recontextualised by the learning community in the context, 
so expertise is the second important factor. The impetus for learning in complex systems is disequilibrium (Cochran-Smith et al. 2014). Teachers in the case study schools were, in effect, destabilised by the demand of becoming pedagogically responsive to diverse learning needs, and this served to drive action and change in thinking and in practice. Continual learning is secured in complex systems through boundary spanning that involves interaction with actors beyond the system (Borzillo and Kaminska-Labbé 2011), and case study schools engaged with university-based teacher educators, the ASSP and community elders to this effect. The third important factor is supportive networking. Complex systems have feedback loops (Clarke and Collins 2007) in which messages travel in non-linear ways through the networks of the community, becoming a powerful tool for learning. The connections developed in learning communities are network structures (Clarke and Collins 2007) which produce supportive relationships.

The contextualised, collaborative learning informed new ways to respond to learner diversity and supported school staff confidence to try inclusive teaching strategies. This means that problems in teaching diverse students can become challenges that collectively can be addressed (Messiou et al. 2016). The new knowledge and skills in inclusive teaching should ultimately benefit learners, especially those who experience difficulties in learning.

\section{Conclusion}

The difficulties that learners have in learning should be seen as catalysts for professional challenges for teachers and the opportunities to develop more inclusive teaching to meet diverse student needs demand a commitment to professional development (Florian and Black-Hawkins 2011, Messiou et al. 2016). Supportive, 
collaborative learning communities seem to be the optimal means to enable this professional development and are better suited to respond to educational challenges. However, to make any claims that inclusive teaching will be realised by the mobilisation of learning communities would be to undermine the complexity of context and of teacher learning (Cochran-Smith et al. 2014). Instead, we propose that if and when learning communities (of whatever variety) emerge or are created to support professional learning for inclusive teaching, there are three factors which can be seen as necessary, though perhaps not sufficient, for their functioning: responsiveness to contextual exigencies matters, expertise matters and supportive networks matter. We have identified these as the things that matter across very different contexts. This is not to say that other factors (like leadership) may not be important, or that a different crosscase analysis would necessarily reveal the same factors. While acknowledging the limitations of the study across only three schools, we are confident in claiming that context matters to the functioning of the group and the development of inclusive practice; internal and external expertise matters to secure ongoing learning; and mutually supportive relationships within the learning communities matter. Having a better understanding of how professional learning works in various cultural and geographical contexts increases our understanding of the need for situated learning to support inclusive teaching for all learners.

\section{Disclosure statement}

No potential conflict of interest was reported by the authors.

\section{Acknowledgement of funding}

The South African work was made possible by a National Research Foundation CSUR grant. The Australian research [Project 2.027RS_PP] was financially supported by the 
Cooperative Research Centre for Living with Autism (Autism CRC), established and supported under the Australian Government's Cooperative Research Centres Program.

\section{References}

Ainscow, M., Booth, T., and Dyson, A., 2006. Improving schools, developing inclusion. Abingdon: Routledge.

Anderson, J.R., Greeno, J.G., Reder, L.M., and Simon, H.E., 2000. Perspectives on learning, thinking and activity. Educational researcher, 29 (4), 11-13.

Australian Research Alliance for Children and Youth, 2013. Inclusive education for students with disability: a review of the best evidence in relation to theory and practice. Australian Government Department of Education. Available from: https://www.aracy.org.au/publicationsresources/command/download_file/id/246/filename/Inclusive_education_for_stu dents_with_disability_A_review_of_the best_evidence_in_relation_to_theory_and_practice.pdf

Berry, B., Johnson, D., and Montgomery, D., 2005. The power of teacher leadership [electronic version]. Educational leadership, 62 (5), 56.

Borko, H., 2004. Professional development and teacher learning: mapping the terrain. Educational researcher, 33 (8), 3-15.

Borzillo, S., and Kaminska-Labbé, R., 2011. Unravelling the dynamics of knowledge creation in communities of practice though complexity theory lenses. Knowledge management research \& practice, 9 (4), 353-366.

Botha, J., and Kourkoutas, E., 2016. A community of practice as an inclusive model to support children with social, emotional and behavioural difficulties in school contexts. International journal of inclusive education, 20 (7), 784-799. 
Brodie, K., 2016. Facilitating professional learning communities in mathematics. In: K. Brodie and H. Borko, eds. Professional learning communities in South African schools and teacher education programmes. Cape Town: HSRC Press, 155-176.

Brodie, K., and Borko, H., 2016. Introduction. In: K. Brodie and H. Borko, eds. Professional learning communities in South African schools and teacher education programmes. Cape Town: HSRC Press, 1-17.

Carrington, S., Tangen, D., and Beutel, D., 2019. Inclusive education in the Asia IndoPacific region. International journal of inclusive education, 23 (1), 1-6.

Chiner, E., and Cardona, M.C., 2013. Inclusive education in Spain: how do skills, resources, and supports affect regular education teachers perceptions of inclusion? International journal of inclusive education, 17 (5), 526-541.

Christ, T., and Wang, X.C., 2013. Exploring a community of practice model for professional development to address challenges to classroom practices in early childhood. Journal of early childhood teacher education, 34 (4), 350-373.

Clarke, A., and Collins, S., 2007. Complexity science and student teacher supervision. Teaching and teacher education, 23, 160-172.

Cochran-Smith, M., et al., 2014. The challenge and promise of complexity theory for teacher education research. Teachers college record, 116 (5), 1-38.

Darkins, A.W., and Cary, M.A., 2000. Telemedicine and telehealth: principles, policies, performance and pitfalls. London: Free Association Books.

Davis, B., and Sumara, D., 2005. Challenging images of knowing: complexity science and educational research. International journal of qualitative studies in education, 18, 305-321.

Duley, P., et al., 2017. The strong family program: an innovative model to engage Aboriginal and Torres Strait Islander youth and elders with reproductive and 
sexual health community education [online]. Health promotion journal of Australia: official journal of Australian Association of Health Promotion Professionals, 28 (2), 132-138.

Engelbrecht, P., et al., 2016. The idealism of education policies and the realities in schools: the implementation of inclusive education in South Africa. International journal of inclusive education, 20 (5), 520-535.

Farnsworth, V., Kleanthous, I., and Wenger-Trayner, E., 2016. Communities of practice as a social theory of learning: a conversation with Etienne Wenger. British journal of educational studies, 64 (2), 139-160.

Florian, L., and Black-Hawkins, K., 2011. Exploring inclusive pedagogy. British educational research journal, 37 (5), 813-828.

Florian, L., and Graham, A., 2014. Can an expanded interpretation of phronesis support teacher professional development for inclusion? Cambridge journal of education, 44 (4), 465-478.

Florian, L., and Rouse, M., 2009. The inclusive practice project in Scotland: teacher education for inclusive education. Teaching and teacher education, 25 (4), 594601.

Forlin, C., 2010. Reframing teacher education for inclusion. In: C. Forlin, ed. Teacher education for inclusion: changing paradigm and innovative approaches. London: Routledge, 3-12.

Gilchrist, G., 2018. Practitioner enquiry: professional development with impact for teachers, schools and systems. London: Taylor and Francis.

Hargreaves, A., and Fullan, M., 2012. Professional capital. New York, NY: Teachers College Press. 
Hofmeyer, J., and Draper, K., 2015. Teachers in South Africa: supply and demand. Johannesburg: The Centre for Development and Enterprise. Available from: http://www.cde.org.za/wp-content/uploads/2015/03/Final-Revised-ESTeacherSupplyandDemand2025.pdf

King, F., 2019. Professional learning: empowering teachers? Professional development in education, 45 (2), 169-172.

King-Sears, M.E., Janney, R., and Snell, M.E., 2000. Teachers' guides to inclusive practices: collaborative teaming. 3rd ed. Baltimore: Brookes Publishing.

Kozleski, E., Artiles, A., and Waitoller, F.R., 2011. Introduction: equity in inclusive education. In: A. Artiles, E. Kozleski, and F.R. Waitoller, eds. Inclusive education: examining equity on five continents. Cambridge, MA: Harvard Education Press, 1-14.

Lave, J., 1991. Situating learning in communities of practice. In: L. Resnick, J. Levine, and S. Teasley, eds. Perspectives on socially shared cognition. Washington, DC: American Psychological Association, 63-82.

Lave, J., and Wenger, E., 1991. Situated learning: legitimate peripheral participation. Cambridge: Cambridge University Press.

Lessing, A., and De Witt, M., 2007. The value of continuous professional development: teachers' perceptions. South African journal of education, 27 (1), 53-56.

Mak, B., and Pun, S.H., 2015. Cultivating a teacher community of practice for sustainable professional development: beyond planned efforts. Teachers and teaching, 21 (1), 4-21.

Matanhire, V., 2017. The facilitator's role in professional learning communities for inclusive education. Unpublished M.Ed Research Report. University of the Witwatersrand, Johannesburg. Available from: 
http://wiredspace.wits.ac.za/bitstream/handle/10539/25940/Vimbayi\%20Matanh ire 762642\%20_\%20M\%20Ed\%20Research\%20report\%2C\%20March\%20201 7.pdf? sequence $=2 \&$ is Allowed $=\mathrm{y}$

Messiou, K., et al., 2016. Learning from differences: a strategy for teacher development in respect to student diversity. School Effectiveness and School Improvement, 27 (1), 45-61.

McMillan, J., and Schumacher, S., 2010. Research in education. 6th ed. New York, NY: Longman.

Ntombela, S., 2011. The progress of inclusive education in South Africa: teachers' experiences in a selected district, KwaZulu-Natal. Improving schools, 14 (1), 514.

Opfer, D., and Pedder, D., 2011. Conceptualizing teacher professional learning. Review of educational research, 81 (3), 376-407.

Pirtle, S.S., and Tobia, E., 2014. Implementing effective professional learning communities. SEDL insights, 2 (3), 1-8.

Robinson, R., and Carrington, S., 2002. Professional development for inclusive schooling. The international journal of educational management, 16 (5), 239247.

Russo, A., 2005. School based coaching. In: C. Chauncey, ed. Recruiting, retaining and supporting highly qualified teachers. Cambridge: Harvard Education Press, $105-114$.

Saggers, B., et al., 2018. Australian autism educational needs analysis - what are the needs of schools, parents and students on the autism spectrum? Full report and executive summary, version 2. Brisbane: Cooperative Research Centre for Living with Autism. 
Sharma, U., Forlin, C., and Loreman, T., 2008. Impact of training on pre-service teachers' attitudes and concerns about inclusive education and sentiments about persons with disabilities. Disability \& society, 23 (7), 773-785.

Slee, R., 2011. The irregular school. Abingdon: Routledge

Spratt, J., and Florian, L., 2013. Applying the principles of inclusive pedagogy in initial teacher education: from university based course to classroom action. Revista de investigación en educación, 11 (3), 133-140.

Stake, R.E., 2006. Multiple case study analysis. New York, NY: Guilford Press.

Swart, E., and Oswald, M., 2008. How teachers navigate their learning in developing inclusive learning communities. Education as change, 12 (2), 91-108.

Szumski, G., Smogorzewska, J., and Karwowski, M., 2017. Academic achievement of students without special educational needs in inclusive classrooms: a metaanalysis. Educational research review, 21, 33-54.

Timperley, H.S., 2011. Realizing the power of professional learning. Maidenhead: McGraw-Hill Education.

Trombly, C.E., 2014. Schools and complexity. An international journal of complexity and education, 11 (1), 40-58.

United Nations (UN), 2006. Convention on the rights and dignity of persons with disabilities. Available from: http://www.un.org/disabilities/documents/convention/convoptprot-e.pdf

United Nations (UN), 2015. Sustainable development goals. New York, NY: United Nations. Available from: http://www.un.org/sustainabledevelopment/summit/ [Accessed January 2018].

United Nations (UN), 2016. General comment no. 4 (2016) on the right to inclusive education. Available from: 
https://tbinternet.ohchr.org/_layouts/treatybodyexternal/Download.aspx?symbol $\underline{\text { no }=\mathrm{CRPD} / \mathrm{C} / \mathrm{GC} / 4 \& \text { Lang }=\mathrm{en}}$

Vangrieken, K., et al., 2017. Teacher communities as a context for professional development: a systematic review. Teaching and teacher education, 61, 47-59.

Vescio, V., Ross, D., and Adams, A., 2008. A review of research on the impact of professional learning communities on teaching practice and student learning. Teaching and teacher education, 24, 80-91.

Victorian Department of Education and Training, 2015. Supporting students with Autism: Building systemic and school capacity. Australian Government Department of Education and Training. Available from: https://docs.education.gov.au/system/files/.../phillipskpa_mssd_final_report_201 5.pdf

Walton, E., 2016. Developing PLCs for inclusive education: a university community engagement opportunity. In: K. Brodie and H. Borko, eds. Professional learning communities in South Africa. Cape Town: HSRC Press, 38-56.

Walton, E., 2018. Decolonising (through) inclusive education? Educational research for social change, $7(0), 31-45$.

Walton, E., et al., 2014. 'You can train us until we are blue in our faces, we are still going to struggle': teacher professional learning in a full-service school. Education as change, 18 (2), 319-333.

Wenger, E., 1998. Communities of practice: learning, meaning, and identity. Cambridge: Cambridge University Press.

Wenger, E., McDermott, R.A., and Snyder, W., 2002. Cultivating communities of practice: a guide to managing knowledge. Boston, MA: Harvard Business Press. 